OPEN ACCESS

Edited by:

Marcella Reale,

University of Studies G. d'Annunzio

Chieti and Pescara, Italy

Reviewed by:

Omar Cauli,

University of Valencia, Spain

Silvia Sánchez-Ramón,

Complutense University of

Madrid, Spain

*Correspondence:

Feng Zhang

zhangfengzmc@163.com

Specialty section:

This article was submitted to

Multiple Sclerosis and

Neuroimmunology,

a section of the journal

Frontiers in Immunology

Received: 13 July 2020 Accepted: 08 September 2020 Published: 15 October 2020

Citation:

Yang Q, Wang G and Zhang F (2020)

Role of Peripheral Immune

Cells-Mediated Inflammation on the

Process of Neurodegenerative

Diseases. Front. Immunol. 11:582825.

doi: 10.3389/fimmu.2020.582825

\section{Role of Peripheral Immune Cells-Mediated Inflammation on the Process of Neurodegenerative Diseases}

\author{
Qiuyu Yang, Guoqing Wang and Feng Zhang* \\ Key Laboratory of Basic Pharmacology of Ministry of Education and Laboratory Animal Center and Joint International \\ Research Laboratory of Ethnomedicine of Ministry of Education, Zunyi Medical University, Zunyi, China
}

Neurodegenerative diseases are characterized by progressive loss of selectively vulnerable neuronal populations, which contrasts with selectively static loss of neurons due to toxic or metabolic disorders. The mechanisms underlying their progressive nature remain unknown. To date, a timely and well-controlled peripheral inflammatory reaction is verified to be essential for neurodegenerative diseases remission. The influence of peripheral inflammation on the central nervous system is closely related to immune cells activation in peripheral blood. The immune cells activation participated in the uncontrolled and prolonged inflammation that drives the chronic progression of neurodegenerative diseases. Thus, the dynamic modulation of this peripheral inflammatory reaction by interrupting the vicious cycle might become a disease-modifying therapeutic strategy for neurodegenerative diseases. This review focused on the role of peripheral immune cells on the pathological progression of neurodegenerative diseases.

Keywords: neurodegenerative diseases, peripheral immune cells, macrophage, dendritic cell, natural killer cell, $\mathrm{T}$ cell, B cell, monocyte

\section{INTRODUCTION}

Neurodegenerative disease is the progressive dysfunction and loss of neurons in the central nervous system (CNS), including Alzheimer's disease (AD), Parkinson's disease (PD) and Multiple Sclerosis (MS) (1). The mechanisms underlying their progressive nature remain unknown. To date, aging and immunity are closely associated with the pathogenesis of neurodegenerative diseases. Immunosenescence refers to the gradual deterioration of the immune system brought on by natural age advancement. It involves both the host's capacity to respond to infections and the development of long-term immune memory, which could accelerate the progression of neurodegenerative diseases (2).

Despite different triggering events, a common feature is brain inflammation (3). It is clear that neuroinflammation during compensatory period is beneficial, which help combat infections, promote tissue repair, remove necrotic cells, shape the brain during development and repair following damage. Upon decompensatory period, a vicious cycle of glial priming and release of pro-inflammatory factors promote neuronal damage (4). On the other hand, chronic inflammation, including chronic intestinal inflammation, diabetes, obesity, and systemic lupus erythema, could 
cause cognitive impairment, learning and memory deficits, and human depression $(5,6)$. Moreover, long-term use of nonsteroidal anti-inflammatory drugs would suppress the peripheral immunity and reduce the incidence of PD by about $50 \%$ (7). In PD mice model, intraperitoneal lipopolysaccharide (LPS) injection combined with intravenous administration of two different recombinant $\alpha$-synuclein ( $\alpha$-syn) pathogenic strains resulted in overactivation of microglia and further promoted the recruitment of leukocytes toward the brain and the spinal cord (8). Likewise, inhibiting migration of $\mathrm{T}$ cells or $\mathrm{B}$ cells into the brain rendered the CNS susceptible to devastating infections. However, the nature of peripheral immune cells in neurodegenerative diseases progression remains unclear. Thus, this review summarized the roles of peripheral immune cells on the pathological progression of neurodegenerative diseases.

\section{ROLES OF PERIPHERAL IMMUNE CELLS ON NEURODEGENERATIVE DISEASES}

\section{Mononuclear Phagocyte System Monocyte}

Monocyte is the largest type of white blood cell in the peripheral blood that could differentiate into macrophages or dendritic cells (DCs) (9). Monocyte triggers innate immune responses by regulating Toll-like receptors (TLRs), scavenger receptors, phagocytosis and complement-mediated responses. Recent studies revealed that gut dysbiosis, a primary element behind various gastrointestinal disorders, might augment LPS, proinflammatory factors and monocytes, thus leading to increased intestinal and blood brain barrier (BBB) permeability through microbiota-gut-brain axis. Correspondingly, accumulation of axonal damage, misfolded proteins and neuronal demyelination facilitates the pathogenesis of neurodegenerative disorders, such as $\mathrm{AD}, \mathrm{PD}$ and $\mathrm{MS}$ (10).

In $\mathrm{AD}$ patients, a higher proportion of monocytes in the peripheral blood was discerned, whereas the interaction between monocytes and platelets in the blood was not altered. Besides, cathepsin D, a major lysosomal aspartic protease, was underexpressed in monocytes, causing the defective degradation of amyloid- $\beta$ (A $\beta$ ) by monocytes (11). However, the sensitivity of monocytes toward $A \beta$ peptides was decreased, indicating that there might be a critical link between the interaction of platelets and monocytes in AD (12).

Transcriptomics analysis showed that monocytes isolated from peripheral blood of PD patients conferred proinflammatory effects. The increase in the number of classical monocytes in PD blood and the decrease in the number of non-classical monocytes might result from the increased monocyte differentiation or increased migration from the bone marrow (13). In contrast, monocytes play an important role in repairing of the injured brain. For example, continuous low-dose injections of LPS in the periphery caused chronic inflammation and the tolerance of peripheral monocytes. Once CNS was stimulated again, dopaminergic neuronal damage was reduced (14). Of note, PD-associated gene DJ-1 deficiency attenuated monocyte infiltration into the damaged brain, which in turn led to delay in repairing of brain injury in mice (15). Furthermore, the chemotaxis and phagocytosis of aged monocytes were increased or decreased under different conditions. In neurodegeneration, an increase in the number of monocytes and functional changes observed in peripheral blood might be related to immunosenescence, but this change was more obvious in age-matched $\mathrm{PD}$ patients (16).

Currently, the blood monocyte counted in the early phase of MS was robustly associated with the clinical severity of MS, whereas the counts of the other blood cells were not related with MS severity (17). Moreover, various animal studies carried out that monocytes contributed to MS-associated neuroinflammation. While classically activated monocytes promoted inflammation, type II-activated monocytes could improve the progression of MS. Furtherly, antioxidant and anti-inflammatory alternatives inhibited monocyte secretion of pro-inflammatory cytokines, such as TNF- $\alpha$, IL-6, and IL- $1 \beta$, and also suppressed the phagocytosis of monocytes and thus slowed down the pathological process of MS (18).

\section{Macrophage}

In the inflammatory lesions, macrophages are the dominant cells. Macrophages in peripheral blood can cross BBB to secrete pro-inflammatory factors in brain to further determine the survival of neurons (19). Production of these inflammatory factors in brain is generally considered to be the primary mechanisms underlying the development of neuronal damage in response to chronic inflammation (20). Additionally, the reninangiotensin system acts on macrophages via different signaling pathways. Angiotensin (Ang) II type 1 receptors (ATR) drive pro-inflammatory macrophage responses in neuroinflammation via regulation of chemokines. Interestingly, macrophages could secrete pro-inflammatory and anti-inflammatory factors due to the autoimmune actions of inflammation (21). In CNS, microglia are the resident macrophages and play vital functions for brain development and homeostasis. The phenotypic differentiation between microglia and peripheral macrophages is verified to be age-dependent. Peripheral macrophages might express several most commonly described microglia markers in some developmental stages or pathological conditions, particularly during chronic neuroinflammation (22). At present, bloodderived macrophages are thought to contribute to brain damage and repair in yet unidentified ways (23).

A number of studies demonstrated that defects of macrophages interfered with brain clearance of $A \beta$, including in $\mathrm{A} \beta$ phagocytosis and $\mathrm{A} \beta$-induced apoptosis. Macrophages derived from peripheral blood in $\mathrm{AD}$ patients were found to possess ineffective phagocytosis of $A \beta$ and low resistance to apoptosis by $\mathrm{A} \beta$ (24-26). Another evidences indicated that IL-34 could impair monocyte differentiation into macrophages and reduce their ability to uptake pathological forms of $A \beta$. Given the critical role of macrophage-mediated $A \beta$ clearance in both murine models and patients with AD, IL-34 might be relevant to innate immune responses in $\mathrm{AD}$ (27). Besides, in clinical studies, the highly reactive compound, methylglyoxal, has been implicated in the development of $\mathrm{AD}$ and methylglyoxal might 
be produced by macrophages during sepsis and further fasten the pathological process of $\mathrm{AD}(28)$.

In addition, modulation of the secretion of anti-inflammatory factors by macrophages might be a reasonable way to control chronic inflammation and delay the progression of neurodegenerative diseases. In PD patients, niacin could reduce the expression level of GPR109a in macrophages and increase the secretion of anti-inflammatory factors by macrophages in blood, that thereby slowing the progression of $\mathrm{PD}(29,30)$. On the other hand, intraperitoneal injection of 1-methyl-4phenyl-1, 2, 3, 6-tetrahydropyridine (MPTP) in mice increased peripheral macrophages levels (31). Also, macrophages can activate PD-related genes, such as LRRK2, by pathogenor sterile-induced endomembrane damage (32). Meanwhile, glial cell-line derived neurotrophic factor (GDNF) delivery mediated by macrophages from bone marrow was confirmed to improve neuroinflammation and inhibit dopaminergic neurodegeneration (33).

Macrophages are the predominant cell type in acute inflammatory brain lesions of MS, which can produce proinflammatory and toxic molecules and promote demyelination, although macrophages of peripheral origin were not normally present in the parenchyma of healthy CNS $(34,35)$. In detail, in response to experimental autoimmune encephalomyelitis (EAE, the induced variant of MS in animals, usually in mice) induction, they were recruited and infiltrated into the CNS and, together with residential microglia, contributed to the pathogenesis of MS (36). Moreover, IL-10 and IL-4 immunoreactivity were shown in active demyelinating lesions and the rim of chronic active lesions of human MS brain, with receptors for these cytokines highly expressed by macrophages in parenchymal and perivascular areas (37). Of note, myelin-laden macrophages expressing high levels of macrophages-associated CD163 and CD206 were discerned in MS patient lesions (38).

\section{Dendritic Cells (DCs)}

DCs had various functions and were recognized as a translator for innate and adaptive immunity. They integrated signals from tissue infection or injury, migrated inflammatory sites and processed antigens to be presented to secondary lymphoid organs. Also, DCs provided a variety of soluble and surfacebound signals to help guide T cell differentiation (39). Generally, decreased number of DCs and decline in DCs functions are the key hallmarks of immunosenescence. Changes of DCs in neurodegenerative diseases patients thus closely resemble classical immunosenescence, and cannot be excluded that neurodegenerative diseases were just characterized by accelerated aging of the immune system.

Multiple studies demonstrated that during inflammation of CNS, activated DCs migrated to cervical lymph nodes, where DCs activated naive lymphocytes and then migrated to the site of inflammation (40). Although DCs were easily found in cerebrospinal fluid, they were not protected by $\mathrm{BBB}$ in the perivascular space. Additionally, the resident or infiltrating DCs exerted anti-inflammatory functions. Intranasal application of vesicular stomatitis virus (VSV) could cause acute infection of CNS. However, in DCs-deficient mice, the interferon- $\gamma(\mathrm{IFN}-\gamma)$ response induced by VSV in CNS was still intact. Therefore, it was still believed that inflammation and certain components of the adaptive primary anti-viral immune response in CNS were dependent on the peripheral DCs in the body (41).

The presence of DCs was still a matter of debate in AD. However, a surprising decline in the population of precursors of DCs in peripheral blood of AD patients with concomitant decline in blood myeloid DCs (MDC) was reported (42). Depletion of DCs by systemic injection of diphtheria toxin, which selectively targeted and eliminated bone-marrow-derived DCs, led to the increased levels of amyloid plaques in $\mathrm{AD}$ animal models. These findings suggested that the peripheral DCs were recruited in the brain and participated in the clearance of amyloid plaques (43). This phenomenon appeared mainly linked to $\mathrm{AD}$ progression and influenced by acetylcholinesterase inhibitors treatment (44). What's more, AD-afflicted hippocampi were also composed of more active DCs and fewer resting DCs than healthy people (45). Furthermore, the activation of DCs prior to the gradual loss of neighboring sensory neurons suggested an early involvement of immune cells in tau-associated pathology originating in CNS (46). Otherwise, studies on the ability of DCs to induce protective immunity to neurodegenerative diseases might have important implications for the development of novel strategies for prophylactic and therapeutic immunizations against microbial pathogens. Vaccination of DCs sensitized to $A \beta$ with a $\mathrm{T}$ cell epitope mutation generated antibody responses in $\mathrm{AD}$ mice (43). These above findings indicated that DCs might play a critical role in the pathogenesis of $\mathrm{AD}$.

In PD patients, the functional changes of DCs in the peripheral system were well-studied. For example, changes in circulating MDC and lymphocyte-like DCs (LDC) on the serum of PD patients were detected. MDC migrated in inflamed tissues and lymph nodes and recognized pathogens. LDC differentiated into typical DCs and mainly produced interferon (47). Recently, it was suggested that peripheral DCs in PD mice model might enter the brain and located in the choroid plexus or meninges and then react with various antigens to promote neuroinflammatory processes (48). In addition, tolerogenic bone marrow-derived DCs induced neuroprotective regulatory $\mathrm{T}$ cells (Tregs) in MPTP-induced PD mice model (49). Surprisingly, dendritic cell factor 1 (DCF1), a membrane protein that plays important roles on nerve development in mouse, could prevent $\alpha$-syninduced dopaminergic neuron loss by aggregating $\alpha$-syn in the dorsomedial region of Drosophila (50).

Migration of DCs to CNS was also a critical event in the pathogenesis of MS. Upon the trafficking of human DCs subsets, circulating MDC and LDC in the blood of MS patients were exhibited, although the exact role of LDC in the pathogenesis of MS remained controversial. Importantly, LDC activation was enhanced in MS and the costimulatory molecules, such as OX40-L, HLA-DR, and CD86 expressed on LDC, could mediate a protective response against the viral trigger of autoimmunity (51). 


\section{Natural Killer (NK) Cell}

NK cells were active members of the innate immunity response system and act as a first-line defense or as non-specific effectors (52). It is found that the number of NK cells increases with age, but changes in NK cells function are less clear. The overwhelming evidence indicated the depressed NK cells function in old individuals. The clinical manifestations attributed to immunosenescence could also be the result of age-dependent alterations in NK cells number and function (53).

At present, the roles of NK cells on the pathogenesis of neurodegenerative diseases were still unilluminated. For example, changes of peripheral NK cells functions in patients with $\mathrm{AD}$ and healthy elderly people were shown, while NK cells killing activity and degranulation (CD107 expression) were unchanged. The underlying mechanisms were unrevealed (54). Moreover, there was no significant difference in the frequency of NK cells in AD patients, but increased spontaneous release of IFN- $\gamma$ and TNF- $\alpha$ from NK cells was exhibited compared to healthy subjects (55). In addition, compared with healthy subjects, circular RNA changes in AD patients, and these RNAs were related to NK cell-mediated cytotoxicity (56). In PD patients, the percentage of NK cells was increased, while the activity of NK cells was not changed (57). Amounts of evidence showed that NK cell levels might be positively associated with the severity of PD (58). Additionally, NK cells modulated $\alpha$-syn pathology and motor symptoms in $\alpha$-syn transgenic mice model (59). Besides, the level of NK cells in peripheral blood of MS patients was increased (60). However, the roles of NK cells on MS were still controversial with studies reporting both protective and damaging roles in MS animal models (61). Collectively, the potential role of NK cells on neurodegenerative diseases warrants deep illustration.

\section{T Cell}

$\mathrm{T}$ cells could penetrate into CNS after being damaged, which affected the activation of glial cells and the degeneration of neurons (62). The activation of $\mathrm{T}$ cells depends on the antigen-presenting cells (APCs). The blood cerebrospinal fluid lacks APCs. APCs are recruited in cerebrospinal fluid of neurodegenerative diseases. Then, APCs present antigens peptides through major histocompatibility complex (MHC) class II molecules to further activate infiltrating $\mathrm{T}$ cells and the process of their surface $\mathrm{T}$ cell receptor (TCR) bound these presented antigen peptides. The TCR-MHC interaction induces the production of $\mathrm{CD}^{+} \mathrm{T}$ cells and $\mathrm{CD}^{+} \mathrm{T}$ cells (63). Undifferentiated $\mathrm{CD} 4^{+} \mathrm{T}$ cells activated by APCs differentiated into different functional phenotypes under different mediators. $\mathrm{CD}^{+}{ }^{+} \mathrm{T}$ cells tended to become T-helper 1 (Th1) phenotype and Th17 inflammatory phenotype, which was closely related to neuroinflammation and neuronal damage (64). On contrast, $\mathrm{CD}^{+}{ }^{+} \mathrm{T}$ cells could differentiate into the functional Th2 and Tregs. These phenotypes played a fundamental role on inhibitory effects on the inflammatory functions of $\mathrm{T}$ cells and the reduction of neuroinflammation $(65,66)$. Recently, as shown in Figure 1, studies indicated that Th1 and Th17 cells secreted pro-inflammatory factors, such as TNF- $\alpha$ and INF- $\gamma$, to induce microglia activation and the subsequent release of other proinflammatory factors (67), whereas Th2 cells and Tregs produced IL-4 and IL-10 to promote the shift of microglia from proinflammatory to anti-inflammatory phenotypes (68).

Fundamentally, brain aging drives systemic aging of whole body, including aging-associated changes of immune system. In turn, the immune system aging, particularly immunosenescence and $\mathrm{T}$ cell aging, initiated by thymic involution that are sources of chronic inflammation in the elderly (termed inflammation), potentially elicits brain aging and neurodegeneration in a reciprocal manner (69). In detail, mounting evidence have also emphasized that peripheral $\mathrm{T}$ lymphocytes played an essential role on the process of neuroinflammation in $\mathrm{AD}$ pathogenesis. Furthermore, role of $\mathrm{A} \beta$-specific $\mathrm{T}$ cells in $\mathrm{AD}$ was bidirectional that they might act in either protective or damaging properties (70). On the other hand, $\mathrm{T}$ cells promoted hippocampal neurogenesis in $\mathrm{AD}$ mice model and $\mathrm{T}$ cells deficiency restricted neuronal regeneration in the hippocampus. The mechanisms underlying the promotion of neuronal regeneration by $\mathrm{T}$ cells were mediated by an up-regulated expression of peripheral $\mathrm{T}$ cells and brain microglial neurotrophic factors release $(71,72)$. Recently, a T-cell population called $\mathrm{CD}^{+}$effector memory CD45RA $^{+} \mathrm{T}$ cells ( $\mathrm{T}_{\mathrm{EMRA}}$ cells) was identified to be closely associated with $\mathrm{AD}$. In cohort of $29 \mathrm{AD}$ patients and 35 healthy controls, $\mathrm{CD}^{+} \mathrm{T}_{\mathrm{EMRA}}$ cells correlated with cognitive dysfunctions, and the presence of these $\mathrm{T}$ cells could predict the disease severity with $80 \%$ accuracy $(73,74)$.

In $\mathrm{PD}$ patients, $\mathrm{T}$ cell levels were down-regulated in peripheral blood (75). Cognitive impairment was associated with higher number of circulating lymphocytes and dysregulation of Tregs compartment (76). It was interesting to note that levels of IL- $1 \beta$, TNF- $\alpha$, IL-2 and peripheral blood lymphocytes in the serum and cerebrospinal fluid of patients with PD were quite high, suggesting $\mathrm{CD}^{+}$and $\mathrm{CD}^{+} \mathrm{T}$ lymphocytes were involved in PD progression (77). In addition, Tregs might exert immunoregulatory functions through the interaction of the peripheral and central immune systems. Indeed, it has been demonstrated that in MPTP-induced PD mouse model, Tregs conferred neuroprotection against dopaminergic neuronal loss in the substantia nigra (78). Similarly, Tregs functions were apparently decreased in the periphery of 6-OHDA-induced $\mathrm{PD}$ rat model, in which $\mathrm{T}$ cell infiltration occurred when neuronal loss in substantia nigra reached $80 \%$ (79). Moreover, a relationship between $\alpha$-syn-specific T cells and PD emerged that the presence of these T cells might be a feature of preclinical and early motor PD (80).

MS was traditionally recognized as a predominantly $\mathrm{T}$ cellmediated autoimmune disease (81). First, the MHC class II allele was known for several decades to be the strongest genetic risk factor for MS. MHC class II proteins were expressed on APCs and required for antigen presentation to $\mathrm{CD} 4^{+} \mathrm{T}$ cells (82). Second, the elevated expression of multiple TGF- $\beta$-targeting miRNAs in naive $\mathrm{CD}^{+} \mathrm{T}$ cells of patients with MS impaired TGF- $\beta$ signaling, and dampened Tregs development, thereby enhancing the susceptibility to developing MS (83). Otherwise, Th cellinduced expression of IL-26 was up-regulated in the blood and cerebrospinal fluid of patients with MS. In EAE, IL-26 reduced 


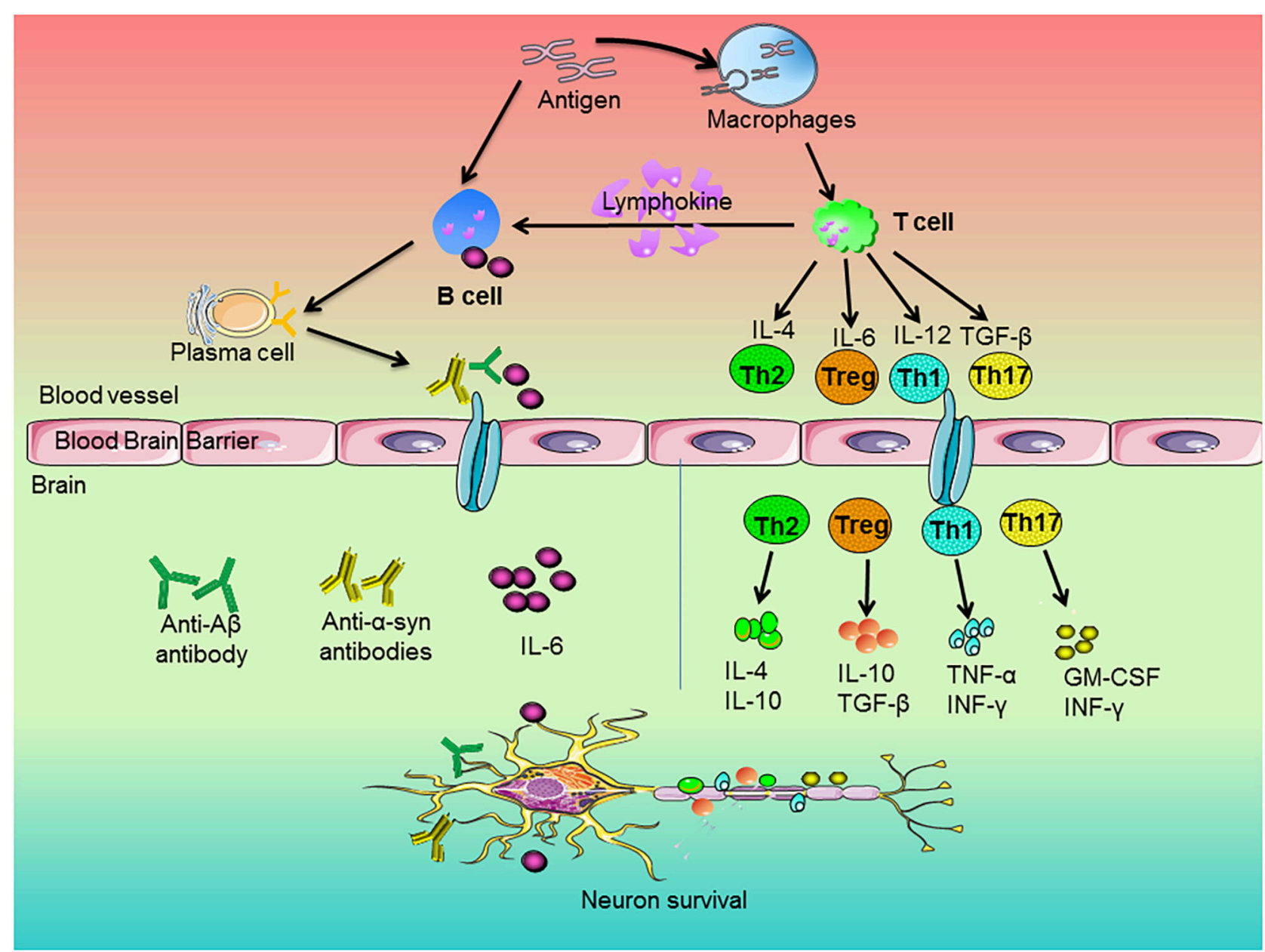

FIGURE 1 | Roles of peripheral immune cells on the pathogenesis of neurodegenerative diseases. The antigen stimulated the immune response of macrophages and B cells. Macrophages engulfed antigens and presented them to T cells. The cytokines of IL-4, IL-6, IL-12, and TGF- $\beta$ released by T cells regulated the development of Th2, Treg, Th1, and Th17 cells, respectively. Then, these cells secreted anti-inflammatory or pro-inflammatory factors to regulate neuronal survival. In addition, antigens could directly stimulate B cells. Upon activation, B cells produced pro-inflammatory factors, which entered the brain along blood vessels and participated in neurodegeneration. On the other hand, activated T cells secreted lymphokines to activate B cells and activated B cells could proliferate and differentiate into plasma cells. Subsequently, the plasma cells-produced cytokines and antibodies, such as anti-A $\beta$ or anti- $\alpha$-synuclein antibodies, went across blood brain barrier and entered the brain and thus attenuated neurons degeneration.

disease severity and pro-inflammatory lymphocyte infiltration into CNS, while increasing infiltration of Tregs $(84,85)$. To date, most studies of the human microbiome have focused on the roles of gut microbiota on MS. Gut microbiota regulates T cell functions throughout whole body. Microbiota transplants from MS patients into germ-free mice resulted in more severe symptoms of EAE and the decreased proportions of IL-10 ${ }^{+}$Tregs (86). On the other hand, higher Th1 and Th17 proportion in MS patients was closly associated with more frequent relapse and more severe clinical disability (87).

\section{B Cell}

$B$ cells are involved in adaptive immunity and considered to be an important component to participate in the pathological process of neurodegenerative diseases (95). Besides, as shown in Figure 1, B cells performed various functions, including the antigen presentation to $\mathrm{T}$ cells, production of pro-inflammatory factors and secretion of anti-inflammatory cytokines (96). In detail, auto-reactive B cells played a pivotal role in autoimmune neurological disorders. B cells released cytokines to promote inflammatory responses of IL- 6 and TNF- $\alpha$ and granulocytemacrophage colony-stimulating factor (GM-CSF) to promote the differentiation of pro-inflammatory factors (97). On the other hand, B cells could secrete IL-10 and IL-35 to exert antiinflammatory effects.

B cell population has been shown to decline due to age, contributing substantially to immunosenescence (98). B cell immunosenescence induces lower antibody specificity. Also, the 
TABLE 1 | Effects of peripheral immune cells on the pathogenesis of neurodegenerative diseases.

\begin{tabular}{|c|c|c|c|}
\hline & Alzheimer's disease (AD) & Parkinson's disease (PD) & Multiple Sclerosis (MS) \\
\hline Monocyte & $\begin{array}{l}\text { - A higher proportion of monocytes in the } \\
\text { peripheral blood (11) } \\
\text { - The sensitivity of monocytes toward } A \beta \\
\text { peptides decreased (12) }\end{array}$ & $\begin{array}{l}\text { - Not only exerted pro-inflammatory effects } \\
\text { but also participated in repair of injured } \\
\text { brain (14) } \\
\text { - The number and function of monocytes } \\
\text { increased in age-matched PD patients (16) }\end{array}$ & $\begin{array}{l}\text { - The counts of blood monocytes associated with } \\
\text { the clinical severity of MS (17) } \\
\text { - Contributed to MS-associated } \\
\text { neuroinflammation (18) }\end{array}$ \\
\hline Macrophage & $\begin{array}{l}\text { - Increased peripheral macrophages in AD } \\
\text { mice (26) } \\
\text { - Mediated the clearance and degradation of } \\
A \beta(24,25)\end{array}$ & $\begin{array}{l}\text { - Increased peripheral macrophages in PD } \\
\text { mice (31) } \\
\text { - Produced pro-inflammatory and } \\
\text { anti-inflammatory factors (30) } \\
\text { - Activated LRRK2 after being stimulated by } \\
\text { pathogens (32) }\end{array}$ & $\begin{array}{l}\text { - Main cell type involved in MS (34) } \\
\text { - Produced pro-inflammatory factors and } \\
\text { promoted demyelination (35) } \\
\text { - Infiltrating macrophages and microglia promoted } \\
\text { the pathogenesis of MS (36) }\end{array}$ \\
\hline Dendritic Cell (DC) & $\begin{array}{l}\text { - Vaccination of DCs sensitized to A } \beta \\
\text { generated antibody responses (43) }\end{array}$ & $\begin{array}{l}\text { - Tolerogenic bone marrow-derived DCs } \\
\text { induced neuroprotective regulatory T cells } \\
\text { (Tregs) (49) }\end{array}$ & $\begin{array}{l}\text { - Circulating myeloid DCs (MDC) and lymphocyte- } \\
\text { like DCs (LDC) in the blood of MS patients } \\
\text { exhibited } \\
\text { - LDC activation enhanced in MS and the } \\
\text { costimulatory molecules expressed on LDC, } \\
\text { mediated a protective response against the viral } \\
\text { trigger of autoimmunity }\end{array}$ \\
\hline Natural Killer (NK) Cell & $\begin{array}{l}\text { - Increased spontaneous release of IFN- } \gamma \\
\text { and TNF- } \alpha \text { from NK cells (55) }\end{array}$ & $\begin{array}{l}\text { - NK cell levels positively associated with the } \\
\text { severity of PD (59)Modulated } \alpha \text {-synuclein } \\
\text { pathology (59) }\end{array}$ & $\begin{array}{l}\text { - The level of NK cells in peripheral blood of MS } \\
\text { patients increased (60) } \\
\text { - Conferred both protective and damaging roles in } \\
\text { MS (61) }\end{array}$ \\
\hline T Cell & $\begin{array}{l}\text { - Might act in either protective or damaging } \\
\text { properties }(70) \\
\text { - Promoted hippocampal neurogenesis in } \\
\text { AD mice }(71,72)\end{array}$ & $\begin{array}{l}\text { - T cell levels down-regulated in peripheral } \\
\text { blood (75) } \\
\text { - Cognitive impairment associated with } \\
\text { higher number of circulating lymphocytes } \\
\text { and dysregulation of Tregs compartment } \\
\text { (76) } \\
\text { - Tregs might exert immunoregulatory } \\
\text { functions through the interaction of the } \\
\text { peripheral and central immune systems } \\
(78,79)\end{array}$ & $\begin{array}{l}\text { - MS traditionally recognized as a predominantly T } \\
\text { cell-mediated autoimmune disease (81). } \\
\text { - Higher Th1 and Th17 proportion in MS patients } \\
\text { closely associated with more frequent relapse } \\
\text { and more severe clinical disability (87) }\end{array}$ \\
\hline B Cell & $\begin{array}{l}\text { - Decreased levels of peripheral B cell } \\
\text { subsets detected in AD patients }(88) \\
\text { - Played an essential role on cerebral } A \beta \\
\text { pathology }(89,90)\end{array}$ & $\begin{array}{l}\text { - Not detected in the brain, while IgG } \\
\text { precipitates found in dopaminergic neurons } \\
\text { and IgG coated in Lewy bodies (91) } \\
\text { - Memory B cell repertoire of PD patients } \\
\text { might represent a potential source for } \\
\text { biomarkers and therapies (92) }\end{array}$ & $\begin{array}{l}\text { - Were discerned in CNS lesions in early to late } \\
\text { stages of MS (93) } \\
\text { - Involved in neuroinflammation of cortical cells, } \\
\text { leading to neuronal death and subpial } \\
\text { demyelination and thus contributing to clinical } \\
\text { progression of MS (94) }\end{array}$ \\
\hline
\end{tabular}

antibody specificity is altered by aging. The impairments affecting $\mathrm{B}$ cells during aging are reduction of $\mathrm{B}$ cell number and decreased sensitivity to antigens. Thus, the senescence of B cells affects the pathological process of neurodegenerative diseases. For example, the decreased levels of peripheral B cell subsets were detected in $\mathrm{AD}$ patients, which might be associated with the genetic changes in these cells (88). Furthermore, differences of levels of anti-A $\beta$ antibodies in serum or cerebrospinal fluid between $\mathrm{AD}$ patients and healthy controls were indicated. These inconsistencies might be related to the increased binding of anti-A $\beta$ antibodies to $A \beta$ in $\mathrm{AD}$ patients $(89,90)$. There is growing evidence that a reduced $A \beta$ pathology was indicated in an amyloid precursor protein (APP) transgenic mouse model of AD lacking functional B cell. Overall, these results demonstrated an essential role Of B cells on cerebral $\mathrm{A} \beta$ pathology.

Additionally, there are several types of receptors on the surface of B cell membranes, which express IgM, IgD, IgG, IgA, and IgE.
These immunoglobulins were important characteristic markers for $B$ cells and bound to the corresponding receptors on immune cells to present different functions. In PD patients, B cells were not detected in the brains, while IgG precipitates were found in dopaminergic neurons and IgG coated in Lewy bodies (91). Although the exact specificity of the transferred IgG antibody was not defined, previous studies confirmed that in passive transfer experiments, a large amount of IgG derived from PD patients caused the gradual loss of selective dopaminergic neurons. Importantly, detection of cell levels in the serum of PD patients demonstrated that the decrease in $\mathrm{CD}^{+}{ }^{+}$Th cells and $\mathrm{CD} 19^{+}$ B cells was worsened with the increased clinical severity (99101). On the other hand, through interrogating peripheral $\mathrm{IgG}^{+}$ memory B cells from PD patients for reactivity to $\alpha$-syn, naturally occurring antibodies derived from PD patients suppressed $\alpha$ syn seeding in vitro and recognized Lewy pathology. This finding suggests that the memory $\mathrm{B}$ cell repertoire of $\mathrm{PD}$ 
patients might represent a potential source for biomarkers and therapies (92).

What's more, B cells could be discerned in CNS lesions in early to late stages of MS and most B cells were confined to the perivascular space (93). B cells in MS were verified to display a pro-inflammatory cytokine profile. Furthermore, in human cytomegalovirus (HCMV)-encoded antigens in patients with MS, B cells from HCMV(-) MS patients induced an enhanced pro-inflammatory profile compared to $\operatorname{HCMV}(+)$ MS cases, suggesting that persistent HCMV infection might reduce the inflammatory responses of B cells in MS (102). Besides, injection of $\mathrm{TNF}^{+}$IFN- $\gamma$ viral vectors elicited extensive $\mathrm{B}$ cells and macrophages infiltration in the meninges. These results implied that B cells could activate TNF signaling pathways in cortical cells leading to neuronal death and subpial demyelination and thus contribute to clinical progression of MS (94). Furthermore, B cell activation inhibitors inhibited the release of pro-inflammatory factors and impaired the capacity of B cells to act as APCs for the development of encephalitogenic $\mathrm{T}$ cells, resulting in selectively interfering with MS (103). In addition, anti-CD20mediated B cell depletion effectively reduced acute MS flares. Currently, all approved MS disease-modifying therapies altered the frequency, phenotype or homing of $\mathrm{B}$ cells in one way or another. The importance of this action has been enhanced by the successful development and clinical testing of B celldepleting monoclonal antibodies targeting the CD20 surface antigen (104). In addition, peripheral $\mathrm{CD} 19^{+} \mathrm{B}$ cells counts and infusion intervals were verified as a surrogate for long-term B cell depleting therapy in MS (105). Together, B cell-directed therapy in MS could be possibly advanced by integrating the

\section{REFERENCES}

1. Stephenson J, Nutma E, van der Valk P, Amor S. Inflammation in CNS neurodegenerative diseases. Immunology. (2018) 154:204-19. doi: 10.1111/imm.12922

2. Costantini E, D'Angelo C, Reale M. The role of immunosenescence in neurodegenerative diseases. Mediators Inflamm. (2018) 2018:6039171. doi: $10.1155 / 2018 / 6039171$

3. Fakhoury M. Role of immunity and inflammation in the pathophysiology of neurodegenerative diseases. Neurodegener Dis. (2015) 15:63-9. doi: $10.1159 / 000369933$

4. Finnie JW. Neuroinflammation: beneficial and detrimental effects after traumatic brain injury. Inflammopharmacology. (2013) 21:309-20. doi: 10.1007/s10787-012-0164-2

5. Chesnokova V, Pechnick RN, Wawrowsky K. Chronic peripheral inflammation, hippocampal neurogenesis, and behavior. Brain Behav Immun. (2016) 58:1-8. doi: 10.1016/j.bbi.2016.01.017

6. Imfeld P, Toovey S, Jick SS, Meier CR. Influenza infections and risk of Alzheimer's disease. Brain Behav Immun. (2016) 57:187-92. doi: 10.1016/j.bbi.2016.03.014

7. Esposito E, Di Matteo V, Benigno A, Pierucci M, Crescimanno G, Di Giovanni G. Non-steroidal anti-inflammatory drugs in Parkinson's disease. Exp Neurol. (2007) 205:295-312. doi: 10.1016/j.expneurol.2007.02.008

8. Peralta Ramos JM, Iribarren P, Bousset L, Melki R, Baekelandt V, Van der Perren A. Peripheral inflammation regulates CNS immune surveillance through the recruitment of inflammatory monocytes upon systemic $\alpha$-synuclein administration. Front Immunol. (2019) 10:80. doi: $10.3389 /$ fimmu. 2019.00080 emerging information on $\mathrm{B}$ cell regulation in MS into future therapeutic avenues.

\section{CONCLUSION}

At present, as shown in Table 1, our understanding of the interaction between peripheral inflammatory mechanisms and neurodegenerative diseases and mutual regulation progressed greatly over decades. Peripheral immune cells are essential but not sufficient to cause neurodegenerative diseases. Additional triggers are clearly necessary for disease onset. Although enormous progress on the etiology of neurodegenerative diseases has been made, further critical investigation is warranted. The dynamic modulation of these peripheral inflammatory reactions by targeting peripheral immune cells might become a diseasemodifying therapeutic strategy for neurodegenerative diseases.

\section{AUTHOR CONTRIBUTIONS}

All authors read, revised, and approved the final manuscript.

\section{FUNDING}

This study was supported by the National Natural Science Foundation of China (no. 81760658), the foundation for Highlevel innovative talents of Guizhou Province (no. 20164027), the Innovation Research Group project of Education Department of Guizhou Province (no. 2016038), and the foundation for Excellent Young Talents of Zunyi Medical University (no. 201603).
9. Dobbs KR, Crabtree JN, Dent AE. Innate immunity to malaria-the role of monocytes. Immunol Rev. (2020) 293:8-24. doi: 10.1111/imr.12830

10. Roy Sarkar S, Banerjee S. Gut microbiota in neurodegenerative disorders. J Neuroimmunol. (2019) 328:98-104. doi: 10.1016/j.jneuroim.2019.01.004

11. Tian L, Zhang K, Tian ZY, Wang T, Shang DS, Li B, et al. Decreased expression of cathepsin $\mathrm{D}$ in monocytes is related to the defective degradation of amyloid- $\beta$ in Alzheimer's disease. J Alzheimers Dis. (2014) 42:511-20. doi: 10.3233/JAD-132192

12. Defrancesco M, Marksteiner J, Humpel C. Reduced beta-amyloid sensitivity for platelet-monocyte aggregates in EDTA blood of alzheimer patients. Int Psychogeriatr. (2018) 30:147-52. doi: 10.1017/S1041610217001612

13. Grozdanov V, Bliederhaeuser C, Ruf WP, Roth V, Fundel-Clemens $\mathrm{K}$, Zondler L, et al. Inflammatory dysregulation of blood monocytes in Parkinson's disease patients. Acta Neuropathol. (2014) 128:651-63. doi: 10.1007/s00401-014-1345-4

14. Liu Y, Xie X, Xia LP, Lv H, Lou F, Ren Y, et al. Peripheral immune tolerance alleviates the intracranial lipopolysaccharide injectioninduced neuroinflammation and protects the dopaminergic neurons from neuroinflammation-related neurotoxicity. J Neuroinflammation. (2017) 14:223. doi: 10.1186/s12974-017-0994-3

15. Choi DJ, Yang H, Gaire S, Lee KA, An JW, Kim BG, et al. Critical roles of astrocytic-CCL2-dependent monocyte infiltration in a DJ-1 knockout mouse model of delayed brain repair. Glia. (2020) 68:2086-101. doi: 10.1002/glia.23828

16. Liang Z, Zhao Y, Ruan L, Zhu LN, Jin KL, Zhuge QC, et al. Impact of aging immune system on neurodegeneration and potential immunotherapies. Prog Neurobiol. (2017) 157:2-28. doi: 10.1016/j.pneurobio.2017. 07.006 
17. Akaishi T, Takahashi T, Nakashima I. Peripheral blood monocyte count at onset may affect the prognosis in multiple sclerosis. J Neuroimmunol. (2018) 319:37-40. doi: 10.1016/j.jneuroim.2018.03.016

18. Fiedler SE, Spain RI, Kim E, Salinthone S. Lipoic acid modulates inflammatory responses of monocytes and monocyte-derived macrophages from healthy and relapsing-remitting multiple sclerosis subjects. Immunol Cell Biol. (2020). doi: 10.1111/imcb.12392. [Epub ahead of print].

19. Wang PL, Yim AKY, Kim KW, Avey D, Czepielewski RS, Colonna $\mathrm{M}$, et al. Peripheral nerve resident macrophages share tissue-specific programming and features of activated microglia. Nat Commun. (2020) 11:2552. doi: 10.1038/s41467-020-16355-w

20. Vichaya EG, Malik S, Sominsky L, Ford BG, Spencer SJ, Dantzer R. Microglia depletion fails to abrogate inflammation-induced sickness in mice and rats. $J$ Neuroinflammation. (2020) 17:172. doi: 10.1186/s12974-020-01832-2

21. Hsieh SW, Huang LC, Chang YP, Hung CH, Yang YH. M2b macrophage subset decrement as an indicator of cognitive function in Alzheimer's disease. Psychiatry Clin Neurosci. (2020) 74:383-91. doi: 10.1111/pcn.13000

22. Grassivaro F, Menon R, Acquaviva M, Ottoboni L, Ruffini F, Bergamaschi $\mathrm{A}$, et al. Convergence between microglia and peripheral macrophages phenotype during development and neuroinflammation. J Neurosci. (2020) 40:784-95. doi: 10.1523/JNEUROSCI.1523-19.2019

23. Hammer A, Stegbauer J, Linker RA. Macrophages in neuroinflammation: role of the renin-angiotensin-system. Pflugers Arch. (2017) 469:431-44. doi: 10.1007/s00424-017-1942-x

24. Jairani PS, Aswathy PM, Krishnan D, Menonet RN, Verghese J, Mathuranath PS, et al. Apolipoprotein E polymorphism and oxidative stress in peripheral blood-derived macrophage-mediated amyloid-beta phagocytosis in Alzheimer's disease patients. Cell Mol Neurobiol. (2019) 39:355-69. doi: 10.1007/s10571-019-00651-1

25. Mammana S, Fagone P, Cavalli E, Basile MS, Petralia MC, Nicoletti F, et al. The role of macrophages in neuroinflammatory and neurodegenerative pathways of Alzheimer's disease, amyotrophic lateral sclerosis, and multiple sclerosis: pathogenetic cellular effectors and potential therapeutic targets. Int J Mol Sci. (2018) 19:831. doi: 10.3390/ijms19030831

26. Kalovyrna N, Apokotou O, Boulekou S, Paouri E, Boutou A, Georgopoulos S. A 3'UTR modification of the TNF- $\alpha$ mouse gene increases peripheral TNF- $\alpha$ and modulates the alzheimer-like phenotype in 5XFAD mice. Sci Rep. (2020) 10:8670. doi: 10.1038/s41598-020-65378-2

27. Zuroff LR, Torbati T, Hart NJ, Fuchs DT, Sheyn J, Rentsendorj A, et al. Effects of IL-34 on macrophage immunological profile in response to Alzheimer's-related $\mathrm{A} \beta_{42}$ assemblies. Front Immunol. (2020) 11:1449. doi: 10.3389/fimmu.2020.01449

28. Prantner D, Nallar S, Richard K, Spiegel D, Collins KD, Vogel SN. Classically activated mouse macrophages produce methylglyoxal that induces a TLR4and RAGE-independent proinflammatory response. J Leukoc Biol. (2020). doi: 10.1002/JLB.3A0520-745RR. [Epub ahead of print].

29. Wakade C, Giri B, Malik A, Khodadadi H, Morgan JC, Chong RK, et al. Niacin modulates macrophage polarization in Parkinson's disease. $J$ Neuroimmunol. (2018) 320:76-9. doi: 10.1016/j.jneuroim.2018.05.002

30. Han X, Sun S, Sun Y, Song QQ, Zhu JL, Song NS, et al. Small molecule-driven NLRP3 inflammation inhibition via interplay between ubiquitination and autophagy: implications for parkinson disease. Autophagy. (2019) 15:186081. doi: 10.1080/15548627.2019.1596481

31. Yan A, Zhang Y, Lin J, Song L, Wang X, Liu Z. Partial depletion of peripheral M1 macrophages reverses motor deficits in MPTP-treated mouse by suppressing neuroinflammation and dopaminergic neurodegeneration. Front Aging Neurosci. (2018) 10:160. doi: 10.3389/fnagi.2018. 00160

32. Herbst S, Campbell P, Harvey J, Bernard EM, Papayannopoulos V, Wood $\mathrm{NW}$, et al. LRRK2 activation controls the repair of damaged endomembranes in macrophages. EMBO J. (2020). doi: 10.15252/embj.2020104494. [Epub ahead of print].

33. Chen C, Li X, Ge G, Liu JW, Biju KC, Laing SD, et al. GDNFexpressing macrophages mitigate loss of dopamine neurons and improve parkinsonian symptoms in mitopark mice. Sci Rep. (2018) 8:5460. doi: 10.1038/s41598-018-23795-4

34. Chrobok NL, Bol JGJM, Wilhelmus MMM, Drukarch B, van Dam AM. Tissue transglutaminase appears in monocytes and macrophages but not in lymphocytes in white matter multiple sclerosis lesions. J Neuropathol Exp Neurol. (2019) 78:492-500. doi: 10.1093/jnen/nlz030

35. Kaunzner UW, Kang Y, Zhang S, Morris E, Yao YH, Pandya S, et al. Quantitative susceptibility mapping identifies inflammation in a subset of chronic multiple sclerosis lesions. Brain. (2019) 142:133-45. doi: 10.1093/brain/awy296

36. Chu F, Shi M, Zheng C, Shen DH, Zhu J, Zheng XY, et al. The roles of macrophages and microglia in multiple sclerosis and experimental autoimmune encephalomyelitis. J Neuroimmunol. (2018) 318:1-7. doi: 10.1016/j.jneuroim.2018.02.015

37. Nally FK, De Santi C, McCoy CE. Nanomodulation of macrophages in multiple sclerosis. Cells. (2019) 8:543. doi: 10.3390/cells8060543

38. Zúñiga-Castillo M, Pereira NV, Sotto MN. High density of M2-macrophages in acral lentiginous melanoma compared to superficial spreading melanoma. Histopathology. (2018) 72:1189-98. doi: 10.1111/his.13478

39. Mildner A, Jung S. Development and function of dendritic cell subsets. Immunity. (2014) 40:642-56. doi: 10.1016/j.immuni.2014.04.016

40. Zozulya AL, Clarkson BD, Ortler S, Fabry Z, Wiendl H. The role of dendritic cells in CNS autoimmunity. J Mol Med. (2010) 88:535-44. doi: 10.1007/s00109-010-0607-4

41. Bourgeois-Daigneault MC, Roy DG, Falls T, Twumasi-Boateng K, StGermain LE, Marguerie M, et al. Oncolytic vesicular stomatitis virus expressing interferon- $\gamma$ has enhanced therapeutic activity. Mol Ther Oncolytics. (2016) 3:16001. doi: 10.1038/mto.2016.1

42. Bossù $P$, Spalletta G, Caltagirone C, Ciaramella A. Myeloid dendritic cells are potential players in human neurodegenerative diseases. Front Immunol. (2015) 6:632. doi: 10.3389/fimmu.2015.00632

43. Brezovakova V, Valachova B, Hanes J, Novak M, Jadhav S. Dendritic cells as an alternate approach for treatment of neurodegenerative disorders. Cell $\mathrm{Mol}$ Neurobiol. (2018) 38:1207-14. doi: 10.1007/s10571-018-0598-1

44. Ciaramella A, Salani F, Bizzoni F, Orfei MD, Caltagirone C, Spalletta $\mathrm{G}$, et al. Myeloid dendritic cells are decreased in peripheral blood of Alzheimer's disease patients in association with disease progression and severity of depressive symptoms. J Neuroinflammation. (2016) 13:18. doi: 10.1186/s12974-016-0483-0

45. Batchu S. In silico analysis of the immunological landscape of hippocampi in Alzheimer's disease. Dement Geriatr Cogn Disord. (2020). doi: 10.1159/000508283. [Epub ahead of print].

46. Jiao $\mathrm{H}$, Downie LE, Huang $\mathrm{X}$, Wu M, Oberrauch S, Keenan RJ, et al. Novel alterations in corneal neuroimmune phenotypes in mice with central nervous system tauopathy. J Neuroinflammation. (2020) 17:136. doi: 10.1186/s12974-020-01803-7

47. Ciaramella A, Salani F, Bizzoni F, Pontieriet FE, Stefanial A, Pierantozzi M, et al. Blood dendritic cell frequency declines in idiopathic parkinson's disease and is associated with motor symptom severity. PLoS ONE. (2013) 8:e65352. doi: 10.1371/journal.pone.0065352

48. Negi N, Das BK. CNS: Not an immunoprivilaged site anymore but a virtual secondary lymphoid organ. Int Rev Immunol. (2018) 37:57-68. doi: 10.1080/08830185.2017.1357719

49. Schutt CR, Gendelman HE, Mosley RL. Tolerogenic bone marrowderived dendritic cells induce neuroprotective regulatory $\mathrm{T}$ cells in a model of Parkinson's disease. Mol Neurodegener. (2018) 13:26. doi: 10.1186/s13024-018-0255-7

50. Zhang S, Feng R, Li Y, Gan LH, Zhou FF, Meng SQ, et al. Degradation of alpha-synuclein by dendritic cell factor 1 delays neurodegeneration and extends lifespan in drosophila. Neurobiol Aging. (2018) 67:67-74. doi: 10.1016/j.neurobiolaging.2018.03.010

51. Corsetti M, Ruocco G, Ruggieri S, Gasperini C, Battistini L, Volpe E. Resiquimod-mediated activation of plasmacytoid dendritic cells is amplified in multiple sclerosis. Int J Mol Sci. (2019) 20:2811. doi: 10.3390/ ijms20112811

52. Berrou J, Fougeray S, Venot M, Chardiny V, Gautier J, Dulphy N, et al. Natural killer cell function, an important target for infection and tumor protection, is impaired in type 2 diabetes. PLoS ONE. (2013) 8:e62418. doi: 10.1371/journal.pone.0062418

53. Aw D, Silva AB, Palmer DB. Immunosenescence: emerging challenges for an ageing population. Immunology. (2007) 120:435-46. doi: 10.1111/j.1365-2567.2007.02555.x 
54. Le Page A, Bourgade K, Lamoureux J, Frost E, Pawelec G, Larbi A, et al. NK cells are activated in amnestic mild cognitive impairment but not in mild Alzheimer's disease patients. J Alzheimers Dis. (2015) 46:93-107. doi: 10.3233/JAD-143054

55. Solerte SB, Cravello L, Ferrari E, Fioravanti M. Overproduction of IFN-gamma and TNF-alpha from natural killer (nk) cells is associated with abnormal nk reactivity and cognitive derangement in Alzheimer's disease. Ann N Y Acad Sci. (2000) 917:331-40. doi: 10.1111/j.1749-6632.2000.tb05399.x

56. Li Y, Fan H, Sun J, et al. Circular RNA expression profile of Alzheimer's disease and its clinical significance as biomarkers for the disease risk and progression. Int J Biochem Cell Biol. (2020) 123:105747. doi: 10.1016/j.biocel.2020.105747

57. Jiang S, Gao H, Luo Q, Wang P, Yang X. The correlation of lymphocyte subsets, natural killer cell, and Parkinson's disease: a meta-analysis. Neurol Sci. (2017) 38:1373-80. doi: 10.1007/s10072-017-2988-4

58. Green H, Zhang X, Tiklova K, Volakakis N, Brodin L, Berg L, et al. Alterations of p11 in brain tissue and peripheral blood leukocytes in Parkinson's disease. Proc Natl Acad Sci USA. (2017) 114:2735-40. doi: 10.1073/pnas.1621218114

59. Earls RH, Menees KB, Chung J, Gutekunst CA, Lee HJ, Hazim MG, et al. NK cells clear $\alpha$-synuclein and the depletion of NK cells exacerbates synuclein pathology in a mouse model of $\alpha$-synucleinopathy. Proc Natl Acad Sci USA. (2020) 117:1762-71. doi: 10.1073/pnas.1909110117

60. Caruana P, Lemmert K, Ribbons K, Lea R, Lechner-Scott J. Natural killer cell subpopulations are associated with MRI activity in a relapsing-remitting multiple sclerosis patient cohort from Australia. Mult Scler. (2017) 23:147987. doi: $10.1177 / 1352458516679267$

61. Bielekova B. Daclizumab therapy for multiple sclerosis. Neurotherapeutics. (2013) 10:55-67. doi: 10.1007/s13311-012-0147-4

62. Mundt S, Greter M, Flügel A, Becher B. The CNS immune landscape from the viewpoint of a $\mathrm{T}$ cell. Trends Neurosci. (2019) 42:667-79. doi: 10.1016/j.tins.2019.07.008

63. Chen Z, Chen S, Liu J. The role of $\mathrm{T}$ cells in the pathogenesis of Parkinson's disease. Prog Neurobiol. (2018) 169:1-23. doi: 10.1016/j.pneurobio.2018.08.002

64. Peck A, Mellins ED. Plasticity of T-cell phenotype and function: the $\mathrm{T}$ helper type 17 example. Immunology. (2010) 129:147-53. doi: 10.1111/j.1365-2567.2009.03189.x

65. Zheng W, Flavell RA. The transcription factor GATA-3 is necessary and sufficient for Th2 cytokine gene expression in CD4 T cells. Cell. (1997) 89:587-96. doi: 10.1016/s0092-8674(00)80240-8

66. Nyström SN, Bourges D, Garry S, Ross EM, van Driel IR, Gleeson PA. Transient Treg-cell depletion in adult mice results in persistent selfreactive CD4(+) T-cell responses. Eur J Immunol. (2014) 44:3621-31. doi: 10.1002/eji.201344432

67. Prajeeth CK, Kronisch J, Khorooshi R, Knier B, Tofthansen H, Gudi V, et al. Effectors of Th1 and Th17 cells act on astrocytes and augment their neuroinflammatory properties. J Neuroinflammation. (2017) 14:204. doi: 10.1186/s12974-017-0978-3

68. González H, Pacheco R. T-cell-mediated regulation of neuroinflammation involved in neurodegenerative diseases. J Neuroinflammation. (2014) 11:201. doi: 10.1186/s12974-014-0201-8

69. Bektas A, Schurman SH, Sen R, Ferrucci L. Human T cell immunosenescence and inflammation in aging. J Leukoc Biol. (2017) 102:977-88. doi: 10.1189/jlb.3RI0716-335R

70. Ethell DW, Shippy D, Cao C, Cracchioloet JR, Runfeldt M, Blakeal B, et al. Abeta-specific T-cells reverse cognitive decline and synaptic loss in Alzheimer's mice. Neurobiol Dis. (2006) 23:351-61. doi: 10.1016/j.nbd.2006.03.008

71. Liu J, Ma Y, Tian S, Zhang L, Zhao MM, Zhang YQ, et al. T cells promote the regeneration of neural precursor cells in the hippocampus of Alzheimer's disease mice. Neural Regen Res. (2014) 9:1541-7. doi: 10.4103/1673-5374.139481

72. Ferretti MT, Merlini M, Späni C, Gericke C, Schweizer N, Enzmann G, et al. T-cell brain infiltration and immature antigen-presenting cells in transgenic models of Alzheimer's disease-like cerebral amyloidosis. Brain Behav Immun. (2016) 54:211-25. doi: 10.1016/j.bbi.2016.02.009
73. Gate D, Saligrama N, Leventhal O, Yang AC, Unger MS, Middeldorp J, et al. Clonally expanded CD8 T cells patrol the cerebrospinal fluid in Alzheimer's disease. Nature. (2020) 577:399-404. doi: 10.1038/s41586-019-1895-7

74. Unger MS, Li E, Scharnagl L, Poupardin R, Altendorfer B, Mrowetz $\mathrm{H}$, et al. $\mathrm{CD}^{+}{ }^{+} \mathrm{T}$-cells infiltrate Alzheimer's disease brains and regulate neuronal- and synapse-related gene expression in APP-PS1 transgenic mice. Brain Behav Immun. (2020) S0889-1591:31573-9. doi: 10.1016/j.bbi.2020. 05.070

75. Álvarez-Luquín DD, Arce-Sillas A, Leyva-Hernández J, Sevilla-Reyes E, Boll MC, Montes-Moratilla E, et al. Regulatory impairment in untreated parkinson's disease is not restricted to tregs: other regulatory populations are also involved. J Neuroinflammation. (2019) 16:212. doi: 10.1186/s12974-019-1606-1

76. Hu ZX, Song WN, Lu XD, Zhou ML, Shao JH. Peripheral T lymphocyte immunity and l-dopamine in patients with Parkinson's disease. J Biol Regul Homeost Agents. (2018) 32:687-91.

77. Brochard V, Combadière B, Prigent A, Laouar Y, Perrin A, Beray-Berthat $\mathrm{V}$, et al. Infiltration of $\mathrm{CD} 4+$ lymphocytes into the brain contributes to neurodegeneration in a mouse model of Parkinson disease. J Clin Invest. (2009) 119:182-92. doi: 10.1172/JCI36470

78. Kim KH, Kim M, Lee J, Jeon HN, Kim SH, Bae H. Comparison of the protective effects of bee venom extracts with varying pla 2 compositions in a mouse model of Parkinson's disease. Toxins. (2019) 11:358. doi: 10.3390/toxins11060358

79. Xiao JJ, Yin M, Wang ZJ, Wang XP. Transplanted neural stem cells: playing a neuroprotective role by ceruloplasmin in the substantia nigra of pd model rats? Oxid Med Cell Longev. (2015) 2015:618631. doi: 10.1155/2015/618631

80. Lindestam Arlehamn CS, Dhanwani R, Pham J, Kuan R, Frazier A, Dutra JR, et al. $\alpha$-synuclein-specific T cell reactivity is associated with preclinical and early Parkinson's disease. Nat Commun. (2020) 11:1875. doi: 10.1038/s41467-020-15626-w

81. Alizadeh-Fanalou S, Alian F, Mohammadhosayni M, Rahban D, Abbasi Ghasem Kheyli P, Ahmadi M. Dysregulation of microRNAs regulating survivin in CD4+ T cells in multiple sclerosis. Mult Scler Relat Disord. (2020) 44:102303. doi: 10.1016/j.msard.2020.102303

82. Kaskow BJ, Baecher-Allan C. Effector T cells in multiple sclerosis. Cold Spring Harb Perspect Med. (2018) 8:a029025. doi: 10.1101/cshperspect. a029025

83. Lee PW, Severin ME, Lovett-Racke AE. TGF- $\beta$ regulation of encephalitogenic and regulatory T cells in multiple sclerosis. Eur J Immunol. (2017) 47:446-53. doi: 10.1002/eji.201646716

84. Broux B, Zandee S, Gowing E, Charabati M, Lécuyer MA, Tastet Olivier, et al. Interleukin-26, preferentially produced by $\mathrm{T}_{\mathrm{H}} 17$ lymphocytes, regulates CNS barrier function. Neurol Neuroimmunol Neuroinflamm. (2020) 7:e870. doi: 10.1212/NXI.0000000000000870

85. Aram J, Frakich N, Morandi E, Alrouji M, Samaraweera A, Onion $D$, et al. Increased IL-2 and reduced TGF- $\beta$ upon T-cell stimulation are associated with GM-CSF upregulation in multiple immune cell types in multiple sclerosis. Biomedicines. (2020) 8:226. doi: 10.3390/ biomedicines 8070226

86. Cekanaviciute E, Yoo BB, Runia TF, Debelius JW, Singh S, Nelson CA, et al. Gut bacteria from multiple sclerosis patients modulate human $\mathrm{T}$ cells and exacerbate symptoms in mouse models. Proc Natl Acad Sci USA. (2017) 114:10713-18. doi: 10.1073/pnas.1711235114

87. Liu J, Mori M, Sugimoto K, Uzawa A, Masuda H, Uchida T, et al. Peripheral blood helper $\mathrm{T}$ cell profiles and their clinical relevance in MOG-IgGassociated and AQP4-IgG-associated disorders and MS. J Neurol Neurosurg Psychiatry. (2020) 91:132-9. doi: 10.1136/jnnp-2019-321988

88. Jiang Q, Jin S, Jiang Y, Liao MZ, Feng RN, Zhang LC, et al. Alzheimer's disease variants with the genome-wide significance are significantly enriched in immune pathways and active in immune cells. Mol Neurobiol. (2017) 54:594-600. doi: 10.1007/s12035-015-9670-8

89. Söllvander S, Ekholm-Pettersson F, Brundin RM, Westman G, Kilander L, Paulie S, et al. Increased number of plasma B cells producing autoantibodies against A $\beta 42$ protofibrils in Alzheimer's disease. J Alzheimers Dis. (2015) 48:63-72. doi: 10.3233/JAD-150236

90. Wang C, Hao J, Liu X, Li CL, Yuan XY, Lee RJ, et al. Isoforsythiaside attenuates Alzheimer's disease via regulating mitochondrial function 
through the PI3K/AKT pathway. Int J Mol Sci. (2020) 21:E5687. doi: $10.3390 /$ ijms 21165687

91. Orr CF, Rowe DB, Mizuno Y, Mori H, Halliday GM. A possible role for humoral immunity in the pathogenesis of Parkinson's disease. Brain. (2005) 128:2665-74. doi: 10.1093/brain/awh625

92. Li X, Koudstaal W, Fletcher L, Costa M, Winsen MV, Siregar B, et al. Naturally occurring antibodies isolated from PD patients inhibit synuclein seeding in vitro and recognize lewy pathology. Acta Neuropathol. (2019) 137:825-36. doi: 10.1007/s00401-019-01974-5

93. Arneth BM. Impact of B cells to the pathophysiology of multiple sclerosis. $J$ Neuroinflammation. (2019) 16:128. doi: 10.1186/s12974-019-1517-1

94. James RE, Schalks R, Browne E, Eleftheriadou I, Munoz CP, Mazarakis ND, et al. Persistent elevation of intrathecal pro-inflammatory cytokines leads to multiple sclerosis-like cortical demyelination and neurodegeneration. Acta Neuropathol Commun. (2020) 8:66. doi: 10.1186/ s40478-020-00938-1

95. Sabatino JJ Jr, Pröbstel AK, Zamvil SS. B cells in autoimmune and neurodegenerative central nervous system diseases. Nat Rev Neurosci. (2019) 20:728-45. doi: 10.1038/s41583-019-0233-2

96. Wortel CM, Heidt S. Regulatory B cells: phenotype, function and role in transplantation. Transpl Immunol. (2017) 41:1-9. doi: 10.1016/j.trim.2017.02.004

97. Vazquez MI, Catalan-Dibene J, Zlotnik A. B cells responses and cytokine production are regulated by their immune microenvironment. Cytokine. (2015) 74:318-26. doi: 10.1016/j.cyto.2015.02.007

98. Cancro MP, Hao Y, Scholz JL, Riley RL, Frasca D, Dunn-Walters DK, et al. B cells and aging: molecules and mechanisms. Trends Immunol. (2009) 30:313-8. doi: 10.1016/j.it.2009.04.005

99. Stevens CH, Rowe D, Morel-Kopp MC, Orr C, Russell T, Ranola M, et al. Reduced T helper and B lymphocytes in Parkinson's disease. J Neuroimmunol. (2012) 252:95-9. doi: 10.1016/j.jneuroim.2012.07.015

100. Ghochikyan A, Petrushina I, Davtyan H, Hovakimyan A, Saing T, Davtyan A, et al. Immunogenicity of epitope vaccines targeting different $B$ cell antigenic determinants of human $\alpha$-synuclein: feasibility study. Neurosci Lett. (2014) 560:86-91. doi: 10.1016/j.neulet.2013.12.028

101. Kobo H, Bar-Shira A, Dahary D, Gan-Or Z, Mirelman A, Goldstein O, et al. Down-regulation of $B$ cell-related genes in peripheral blood leukocytes of Parkinson's disease patients with and without GBA mutations. Mol Genet Metab. (2016) 117:179-85. doi: 10.1016/j.ymgme.2015.09.005

102. Zabalza A, Vera A, Alari-Pahissa E, Munteis E, Moreira A, Yélamos J, et al. Impact of cytomegalovirus infection on B cell differentiation and cytokine production in multiple sclerosis. J Neuroinflammation. (2020) 17:161. doi: 10.1186/s12974-020-01840-2

103. Kinzel S, Weber MS. B cell-directed therapeutics in multiple sclerosis: rationale and clinical evidence. CNS Drugs. (2016) 30:1137-48. doi: 10.1007/s40263-016-0396-6

104. Sabatino JJ Jr, Zamvil SS, Hauser SL. B-cell therapies in multiple sclerosis. Cold Spring Harb Perspect Med. (2019) 9:a032037. doi: 10.1101/cshperspect.a03203

105. Ellrichmann G, Bolz J, Peschke M, Duscha A, Hellwig K, Lee $\mathrm{DH}$, et al. Peripheral $\mathrm{CD}_{1} 9^{+}$B-cell counts and infusion intervals as a surrogate for long-term B-cell depleting therapy in multiple sclerosis and neuromyelitis optica/neuromyelitis optica spectrum disorders. J Neurol. (2019) 266:57-67. doi: 10.1007/ s00415-018-9092-4

Conflict of Interest: The authors declare that the research was conducted in the absence of any commercial or financial relationships that could be construed as a potential conflict of interest.

Copyright $\odot 2020$ Yang, Wang and Zhang. This is an open-access article distributed under the terms of the Creative Commons Attribution License (CC BY). The use, distribution or reproduction in other forums is permitted, provided the original author(s) and the copyright owner(s) are credited and that the original publication in this journal is cited, in accordance with accepted academic practice. No use, distribution or reproduction is permitted which does not comply with these terms. 